\title{
Measuring the bore straightness during reaming with sensoric tools
}

\author{
Andreas Bretz ${ }^{1}$ Eberhard Abele ${ }^{1} \cdot$ Matthias Weigold ${ }^{1}[0$
}

Received: 29 April 2020 / Accepted: 4 August 2020 / Published online: 2 September 2020

(c) The Author(s) 2020

\begin{abstract}
Reaming plays a crucial role in production to meet the high quality requirements of precision bore machining. It is either directly responsible for the final component quality or influences subsequent processes such as honing. The narrow tolerances are usually monitored by measuring random samples in mass production due to cost efficiency. Having a closer look at an exemplary process chain for the production of hydraulic valves shows the possibility to adapt the honing parameters which reduces processing time and costs. However, the bore straightness after the reaming process has to be known. In this paper an approach is presented which allows to record the bore straightness within the productive time. For this purpose, a sensory reaming system is developed. It can be used without additional components in the machine tool and thus integrated into existing machining processes. Cutting tests show that the system is able to measure the bore straightness as good as sensing probes used in machine tools.
\end{abstract}

Keywords Reaming $\cdot$ Sensoric tools $\cdot$ Process monitoring

\section{Introduction}

The production of precision bores by reaming is an essential part of many manufacturing processes. Parts with strict tolerances can be found in combustion engines, hydraulic components, the dental technology as well as in the mechanical and plant engineering. However, high requirements on the reaming process to ensure component quality are in conflict with the parameters time and costs.

The bore quality can be monitored by measuring the parts on coordinate measuring machines (CMM). To do this, the components must first be cleaned to remove residues of chips and cooling lubricants. The non-value-adding time required for cleaning and measuring leads to higher costs. Therefore, a $100 \%$ inspection of the parts is only carried out if it is absolutely necessary for safety-relevant components.

Matthias Weigold

m.weigold@ptw.tu-darmstadt.de

1 Institute of Production Management, Technology and Machine Tools (PTW) of Technische Universität Darmstadt, Otto-Berndt-Straße 2, 64287 Darmstadt, Germany

\section{State of the art}

Reaming as a manufacturing process for the production of precision bores is characterized by low cutting depths and resulting low process forces. In the past, mostly singlebladed reamers were used because higher cutting speeds and better hole quality could be achieved. On the one hand more and more multi-bladed reamers are used as they can compensate for the lower cutting speed by a larger feed per revolution. On the other hand, they have even overtaken single-bladed reamers in the cutting speeds, as a research in the product range of different manufacturers shows [10].

In contrast to turning and milling, reaming is receiving less attention in science, as shown in various review publications [4, 17]. Scientific work is mainly concerned with the simulation of the process for optimizing the reamer design or the determination of ideal cutting parameters to improve the quality of the bore.

A comprehensive analytical model of the reaming process is developed in $[6,7]$. In addition to a detailed description of chip formation, it also includes possible process errors such as misalignment and concentricity errors as well as angular errors of the reamer or the spindle. The comparison with experimental tests shows that the model calculates the feed force and the torque in most cases with a deviation of less than $7 \%$. While the peak-valley values of the forces in the 
$\mathrm{x}$ - and $\mathrm{y}$-direction differ by a maximum of $11 \%$, the mean values show deviations of up to $30 \%$. However, these deviations are not suitable to describe the route of the reamer in the bore exactly.

To predict the cylindricity, a regression model that takes cutting speed, feed rate and the feed during reamer pullout into account is created by [21]. Attempts to calibrate the model show that higher pullout speeds lead to better cylindricity. Furthermore, a strong dependence of cylindricity on the feed is indicated. The coefficient of determination of the model is only $R^{2}=0.644$, so cylindricity can not be accurately predicted by the process parameters. Therefore, process models of the reaming process are not suitable to predict the bore quality.

There are different possibilities to monitor cutting processes, which will be further described in the following. The measurement location has a great influence on the informative value of the obtained data. Measurement should take place as close as possible to the cutting process. As the distance to the cutting zone increases, the number of components involved increases. Each component has its own transfer function which influences the signal and causes additional uncertainty by changing behaviour over time. On the other hand, the closer the measuring system is to the process, the greater is the complexity of sensor integration. The available space in tools and tool holders is severely limited and the systems must be protected against the influence of chips, coolant and the high temperatures prevailing in the cutting zone [11]. Furthermore, the power supply of the measuring systems and the data transmission in the tool or tool holder within rotating systems pose a great challenge.

In several researches strain gauges are attached to frames and slides $[8,15,16]$. However, the advantage of simple integration causes the disadvantage of only a low resolution of the process forces to be measured.

Compared to the machine axes and the frame, the motor spindle is closer to the cutting process. A force-measuring ring with piezo sensors is inserted between the motor spindle and the spindle holder in [23]. For milling tests in the speed range up to $2000 \mathrm{rpm}$, deviations of less than $5 \%$ occur in the measured process forces in comparison to a reference dynamometer under the workpiece. However, the additional compliance of the force-measuring ring leads to a large increase in the dynamic compliance, whereby the use at higher speeds is not possible. An additional sensor ring on the front spindle bearing allows the measurement of the axial force [12]. However, the ring also sensitively reacts to traversing movements of the $\mathrm{z}$-axis and has a high crosstalk when moving the $\mathrm{x}$ - and $\mathrm{y}$-axes. The displacement of the spindle shaft can be measured by means of integrated eddy current sensors [25, 44]. Eddy current sensors to measure the displacement in axial and radial direction are also used in [9]. The process forces are calculated by using pre-determined frequency-response-functions for milling operations. A sensory spindle bearing is now commercially available from the company Schaeffler [39]. It measures not only the radial shaft displacement but also bearing temperature and speed.

Acceleration sensors, which are integrated into the motor spindle or additionally attached, detect vibrations caused by the machining process. Unstable process states or tool breakage can be detected in different processes such as milling [1], drilling [19] or turning [40]. The combination of different sensor systems provides better results than the observation of individual sensors [33].

Stationary systems for measuring the cutting forces between the workpiece and the machine table have been state of the art in machine tools for many years and are commercially available from manufacturers [14]. Nevertheless, there are still publications dealing with the redevelopment of such force measuring platforms [35, 53], partly with a focus on special applications such as broaching [27].

When considering sensory tool holders, two cases have to be distinguished: stationary holders, as used in turning, and rotating tool chucks for use with rotating tools, such as milling, drilling, etc. For stationary tool systems, there are a large number of developments for detecting the occurring process forces, which differ in the measurement principles such as strain gauges, capacitive measurement or piezoelectric sensors [30, 34, 43, 48, 51].

For rotating tool holders, the energy and data transmission must be wireless. The higher development effort compared to stationary systems explains why there are less publications in this area. A tool holder with strain gauges for measuring the torque is developed in [46]. The energy transfer takes place inductively, the data transfer optically. A completely inductive system with piezo sensors especially for HSC machining is developed in [45, 50]. Another similar sensory tool holder is presented by [42]. A system with capacitive force sensors is developed in [52]. The integration of acceleration sensors into a standard tool holder without interfering contours is investigated in [2].

As with stationary holders and force measurement platforms, rotating sensory tool holders are commercially available. For example, systems for measuring the cutting forces and the torque [26] or for measuring the torque, feed force and bending moment [41] are available. However, they are not used in series production due to the high prices, as such systems currently cost a medium five-digit euro amount.

Process monitoring with the least influence of disturbance variables is possible by means of sensory tools. Every second cutting edge on an 8-flute cutter with $125 \mathrm{~mm}$ diameter is removed to weaken the tool and provide room for gluing strain gauges to measure cutting and feed forces in [3]. Strain gauges are also glued to a milling head to measure the process forces by [36]. A large end miller (diameter $100 \mathrm{~mm}$ ) is 
used to integrate sensors in [28, 29, 49]. The triaxial force sensors mounted under each cutting plate allow single cutting force measurement. The data and energy are transmitted inductively. Two sensory cutters with acceleration sensors are developed in [5]. The measured accelerations are used to adapt the process parameters during milling and thus always ensure a stable process state.

As described, there are a large number of solutions for measuring process data during machining, especially for turning and milling processes. In contrast, only few studies dealing with reaming exist. This can also be seen in review and keynote publications, such as [34, 47].

Especially with process monitoring on reaming deals [38]. It is investigated how structure-borne sound signals correlate with chip formation. A clear correlation between chip form and structure-borne sound signal can not be found. In an additional work, the sensor technology is extended by a dynamometer for detecting feed force and torque as well as an acceleration sensor on the workpiece [37]. Roughness, roundness error and remaining residual stress of each bore are measured and used together with the measurement data of the sensors to train an artificial neural network.

In $[31,32]$ an expandable reamer with an actuator for adjusting the diameter is developed. The energy is supplied by accumulators, which are integrated in the holder. The control signals are sent to the tool via Bluetooth. For automatic wear detection, strain gauges should be used to monitor the torque. However, final test results are not presented.

As the state of the art shows, a large number of sensory solutions for process monitoring already exist. However, they all have in common that they are not suitable for measuring the straightness of holes in the reaming process. In many cases, they cover a large number of manufacturing processes, which is why they are also designed for large process forces, such as those that occur in milling and turning processes. When sensors are integrated into the tool chuck or the motor spindle, the rigidity of the system must be retained, which is why they don't have the required sensitivity for the reaming process with its low process forces and deflections. The low process forces are also the reason that cutting models the calculation of measured forces with the help of cutting models don't deliver sufficient accuracy predicting the actual straightness of the bore.

\section{Development of a sensoric reamer}

As shown, there are currently no systems specifically designed to monitor the reaming process. Therefore, the development of a new sensory reamer system is presented. It allows to measure the straightness of the bore during the machining process without any auxiliary process times. The system is structured in different sub-functions as shown in
Fig. 1. Sub functions (SF) 1-5 will be further explained in the following.

\subsection{Measurement data acquisition with strain gauges}

The displacement of the reamer head is measured by using strain gauges which are be applied to the reamer shaft. A first estimation of the strain occurring is made by considering the deflection curve of the reamer. The Euler-Bernoulli beam theory is used.

With the equation

$\varepsilon_{x}(x, z)=u^{\prime}(x)-w^{\prime \prime}(x) z$

the strain $\varepsilon$ can be calculated by using the derivates of the displacements $u$ and $w$ in the $\mathrm{x}$ - and z-direction. The feed force of the reaming process acts as a normal force on the reamer and leads to constant strain

$u^{\prime}(x)=\frac{F_{\mathrm{f}}}{E A}$,

where $E$ is the Young's modulus and $A$ the cross section. For further simplification the cross section is assumed to be constant. In the following, two cases are distinguished for calculating the deflection curve $w(x, z)$, since it is not known how the reamer moves in the bore. In the first case, no rotation of the reamer head around the y-axis is allowed, in the second case this is possible. Both cases with the corresponding strain are shown in Fig. 2. The deflection curve in the first case is

$w(x)=-\frac{2 w_{1}}{L^{3}} x^{3}+3 \frac{w_{1}}{L^{2}} x^{2}$

and its second derivative

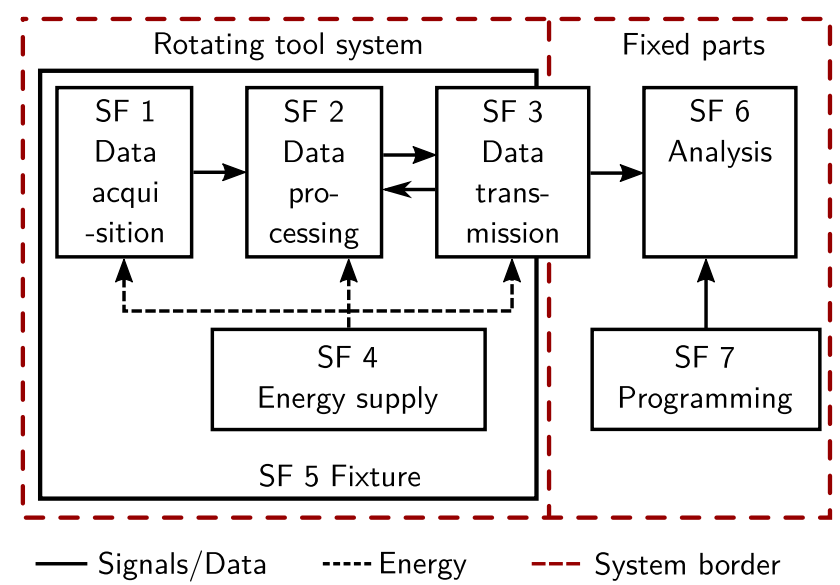

Fig. 1 Structure of the sensory reaming system with sub-functions 


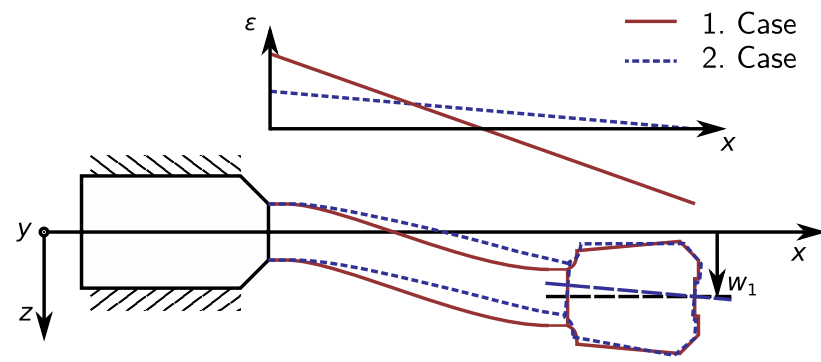

Fig. 2 Comparison of the strains along the reamer for the two cases

$w^{\prime \prime}(x)=\frac{6 w_{1}}{L^{3}}(L-2 x)$.

In the second case it is

$w(x)=-\frac{w_{1}}{2 L^{3}} x^{3}+\frac{3 w_{1}}{2 L^{2}} x^{2}$

with the second derivative

$w^{\prime \prime}(x)=\frac{3 w_{1}}{L^{3}}(L-x)$.

In both cases, the strain has its largest value at the clamping point. In the first case, however, it has a sign change in the middle of the reamer, while in the second case it drops constantly and becomes zero at the head. The maximum strain occurs at the clamping point, which is why the strain gauges are placed there. In preliminary experiments, deflections of the reamer of up to $w_{1}=49 \mu \mathrm{m}$ were measured. With a radius of $5.5 \mathrm{~mm}$ at the reamer shaft and substituting the Eqs. 4 and 6 in Eq. 1 yields a maximum elongation of

$\varepsilon=1.37 \cdot 10^{-4} \hat{=} 1.37 \cdot 10^{-2} \%$.

According to the analytical estimation, strains of less than $2.86 \cdot 10^{-4} \%$ must be recorded in order to measure displacements of the reamer smaller than $1 \mu \mathrm{m}$.

Two measuring bridges are provided to detect the movement behaviour of the reamer in the bore parallel to the working plane. These are located as close as possible to the shaft and are placed offset by $90^{\circ}$. As it is uncertain which of the two cases described applies to reaming, a third measuring bridge is mounted as close as possible to the replaceable head. It is aligned with the first bridge in order to be able to detect the strain course along the reamer. In the first case, both bridges would have different signs. In the second case, the sign would be the same, but the measured values of the third bridge would be significantly lower. Figure 3 shows the positions of the Wheatstone bridges on the reamer.

In addition to the analytical estimation, a finite element simulation is performed to confirm the calculation results.

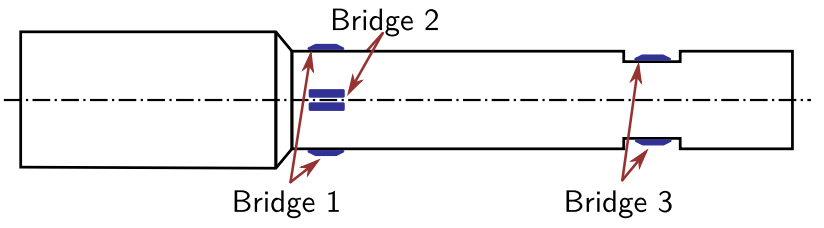

Fig. 3 Arrangement of the measuring bridges on the reame

Table 1 compares the results of the analytical calculation and the simulation for both cases. The deviations between the two calculation methods are the result of the differences between the detail geometry of the reamer and the simple bending beam which is considered for the analytical calculation.

The connection of the strain gauges in the form of a Wheatstone full bridge offers several advantages. On the one hand, temperature influences and normal forces as well as stresses caused by torque are compensated, on the other hand the output voltage of the measuring bridge is increased. The bridge voltage $U_{\mathrm{B}}$ is determined for a typical supply voltage of $U_{\mathrm{S}}=3 \mathrm{~V}$. The strain is assumed to be $\varepsilon=2.86 \cdot 10^{-4} \%$, which occurs with a deflection of the reamer of $1 \mu \mathrm{m}$. For metal strain gauges with a gauge factor of 2 , the result is a voltage change of $\Delta U_{\mathrm{B}}=1.72 \cdot 10^{-5} \mathrm{~V}$ or $1.20 \cdot 10^{-3} \mathrm{~V}$ for semiconductor strain gauges with a gauge factor of 140 . Due to the higher output voltage, the system will be designed with semiconductor strain gauges.

\subsection{Signal processing}

A telemetry unit for the analogue and digital processing of the signals is developed which is specially adapted to the requirements of process monitoring during reaming. It contains the subfunctions 2 and 3 (see Fig. 6). The signal flow is shown in Fig. 4. The required components are placed on a circuit board in order to obtain a compact assembly, which is then fastened through the housing on the tool chuck.

The signals of the measuring bridges are first filtered by a low-pass filter in order to prevent aliasing effects. This is followed by an amplification of the signal. For this purpose, a programmable signal conditioner type PGA309 Texas Instruments is used. The amplification is realized in several stages, wherein the bridge signal is first subjected to an offset correction. This is followed by a first amplification before

Table 1 Comparison of the analytically calculated and simulated strain values

\begin{tabular}{llll}
\hline Strain & Analytical & Simulative & Difference \\
\hline 1. Case & $4.9 \cdot 10^{-3} \%$ & $5.2 \cdot 10^{-3} \%$ & $6 \%$ \\
2. Case & $2.4 \cdot 10^{-3} \%$ & $2.5 \cdot 10^{-3} \%$ & $4 \%$ \\
\hline
\end{tabular}




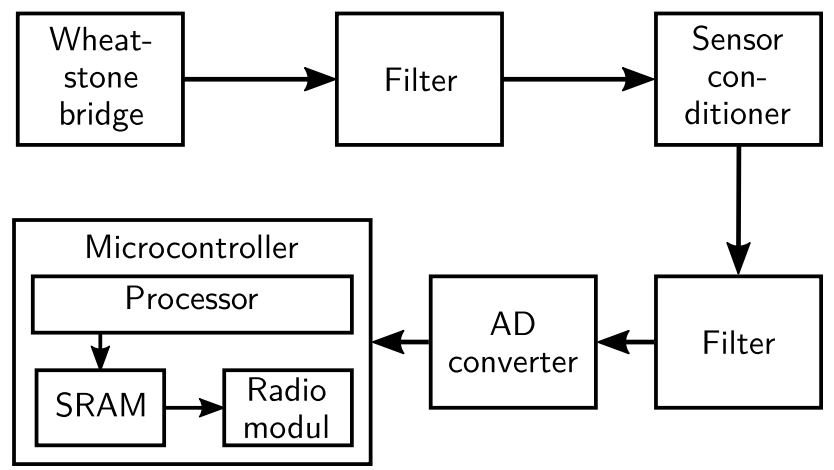

Fig. 4 Signal processing

a further offset adjustment takes place. This is necessary in order to make full use of the input range of the AD converter during the subsequent digitization. Finally, an output gain can be set.

The amplification is followed by another low-pass filtering before the $\mathrm{AD}$ conversion takes place. The selected $\mathrm{AD}$ Converter from Analog Devices AD7682 has four input channels and a sampling rate of 250 kilo samples per second, giving the three channels a maximum sampling rate of $83.3 \mathrm{kHz}$. The resolution is 16 bits, which corresponds to a resolution of $46 \mu \mathrm{V}$ for a range of the input voltage of $3 \mathrm{~V}$.

As a central element, the microcontroller is responsible for the control of the entire board. Its tasks include the initiation of the $\mathrm{AD}$ conversion, reading data of the $\mathrm{AD}$ converter, the following preprocessing and the final transfer to the transmitting unit. An ATMEGA256-RRF2 microcontroller from Microchip, formerly ATMEL, is used. Each conversion and subsequent transfer of the data from the $\mathrm{AD}$ converter to the microcontroller requires $2.2 \mu \mathrm{s}$ for the conversion and $4.0 \mu \mathrm{s}$ for the transfer. The $6.2 \mu \mathrm{s}$ offset between two scans results in a rotation of the reamer around $6.7 \cdot 10^{-20}$, so the error due to rotation can be neglected.

The ZigBee protocol used for data transmission has the advantage that it works with very few additional header bytes. Therefore, the net data rate is relatively large even when sending short packets compared to Bluetooth and WiFi. The usage of ZigBee in machine tools was already investigated in [24], where commercially available modules were used. In contrast, data is only emitted by means of a rod antenna which transmits in the $2.4 \mathrm{GHz}$ range. Due to the radiation characteristics, it is important that the installation does not take place in radial direction, as the directional diagram has its minima at the angles $0^{\circ}$ and $180^{\circ}$. The antenna gain is maximally $3 \mathrm{dBi}$. On the receiver side, an XBee module is used. It can receive signals up to a minimum signal strength of $-92 \mathrm{dBm}$ and forwards the data via a serial interface to a computer for evaluation. Figure 5 shows the developed telemetry unit. It has four layers where the two middle layers are used for power supply.

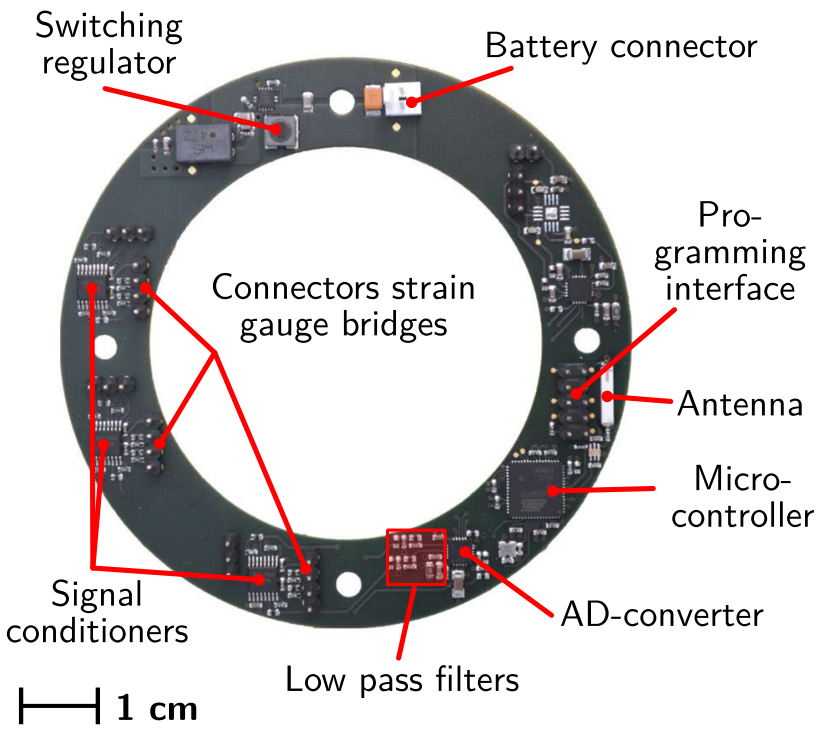

Fig. 5 Circuit board with the elements for data processing

\subsection{Energy supply and housing}

The system is powered by batteries. If the system is active and samples the gauges at a frequency of $1 \mathrm{kHz}$, a current of approx. $48 \mathrm{~mA}$ will flow during radio transmission of the data at a voltage of $3.3 \mathrm{~V}$. At times when there is no transmission, the current drops to $34 \mathrm{~mA}$. The batteries used have a rated voltage of $3.6 \mathrm{~V}$ and a capacity of $1.1 \mathrm{Ah}$, allowing a battery to power the system for around 23 hours of continuous radio transmission. To reduce the imbalance of the system, two batteries are connected in parallel and placed on opposite sides of the housing.

The attachment of the telemetry unit and batteries takes place in a housing, which in turn is placed on the tool chuck. In order not to interfere with the data transfer, it is made of plastic. In addition, due to the low density $\left(1.41 \mathrm{~g} / \mathrm{cm}^{3}\right)$, it has a lower moment of inertia than a comparable metal housing. It was designed for a maximum rotational speed of $10,000 \mathrm{rpm}$ which is nearly double the normal rotational speed used during reaming.

\subsection{Assembly of the entire system}

The completed system is shown in Fig. 6. For a better overview, the housing wall and the housing cover have been omitted. To protect the strain gauges, which are glued on the reamer shaft, against chips and coolants, a protective sleeve is pushed over them and sealed by potting compound. 


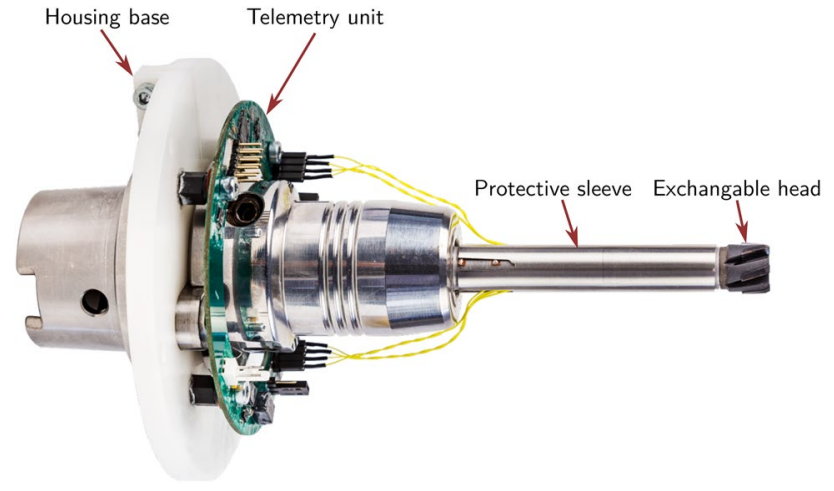

Fig. 6 Sensoric reaming system consisting of tool chuck, reamer with exchangable head, telemetry unit, strain gauge measuring bridges and housing

\section{Analyzing the performance}

Before the system is used in reaming tests, basic functionalities are checked and the performance is evaluated.

\subsection{Noise behaviour of the strain gauges}

Since semiconductor DMS have a higher tendency to noise than metal strain gauges (sg), they are first compared in the laboratory with a test-applied bridge made of metal strain gauges. In a next step, the bridge signals are measured while rotating in the machine tool. For this purpose, the reamer with telemetry unit is installed in the housing and inserted into the motor spindle. The measurements are made with the later used processing rotational speed of $n=1,700 \mathrm{rpm}$. The peak-valley value $U_{\mathrm{PV}}$ and the effective value $U_{\mathrm{RMS}}$ of the measurement noise are recorded for each bridge, the corresponding results are shown in Table 2 .

Under laboratory conditions, the semiconductor strain gauges show, as expected, a higher noise than the metal strain gauges. However, the increase of around $27 \%$ of the peak-valley value or $33 \%$ of the RMS value is negligible compared to the higher bridge reinforcement of $6829 \%$. When used in the machine tool while rotating, there is an

Table 2 Comparison of maximum values of the measuring bridge noise

\begin{tabular}{llll}
\hline Setting & Lab & Machine tool \\
\cline { 2 - 3 } Measured value & $\begin{array}{l}\text { Semi-conductor } \\
\text { strain gauges }\end{array}$ & $\begin{array}{l}\text { Metal strain } \\
\text { gauges }\end{array}$ & $\begin{array}{l}\text { Semi-con- } \\
\text { ductor strain } \\
\text { gauges }\end{array}$ \\
\hline$U_{\mathrm{PV}}$ in $\mathrm{mV}$ & 0.19 & 0.15 & 0.23 \\
$U_{\mathrm{RMS}}$ in $\mathrm{mV}$ & 0.03 & 0.02 & 0.04 \\
\hline
\end{tabular}

increase in noise due to the larger electromagnetic interference fields through the motor spindle. The peak-valley value with a maximum of $0.23 \mathrm{mV}$ is significantly below the expected measurement value of $1 \mathrm{mV}$, which was assumed for a displacement of $1 \mu \mathrm{m}$.

\subsection{Static behaviour}

In the next step, the static behaviour of the Wheatstone bridges is examined. These tests show the quality of the adhesive bond in terms of transfer of strain to the strain gauges. For this purpose, the system is inserted into a motor spindle and the reamer deflected statically at the head. In each case the three occurring bridge voltages are measured as a function of the deflection. Figure 7 shows the measured values.

The tests are repeated five times each, the deviations between the individual measurements amount to less than $0.5 \%$. For bridge 1 , the bridge voltage at a deflection of $72 \mu \mathrm{m}$ is $72 \mathrm{mV}$ and for bridge $321 \mathrm{mV}$. For measurements in the direction of bridge 2 , the voltage of bridge 2 at the same deflection is $70 \mathrm{mV}$. The sensitivity of bridge 2 is thus slightly lower than that of bridge 1 . At the same time it reacts more strongly to loads across the alignment, which is due to a non-exact alignment of the strain gauges.

The difference between the theoretically, from the FEM calculated, and the actually measured strain is around $14 \%$ for Wheatstone brigdes 1 and 2 and $10 \%$ for Wheatstone bridge 3 . The deviations are due to simplifications in the modelling and to the adhesive layer. Overall, the strain of the reamer is measured sufficiently accurate.

\subsection{Test of the radio transmission}

The functionality of the radio transmission is tested by measuring the signal strength of the Received Signal Strength Indication (RSSI) under different conditions. In a laboratory setup, the antenna is first aligned parallel to the receiving

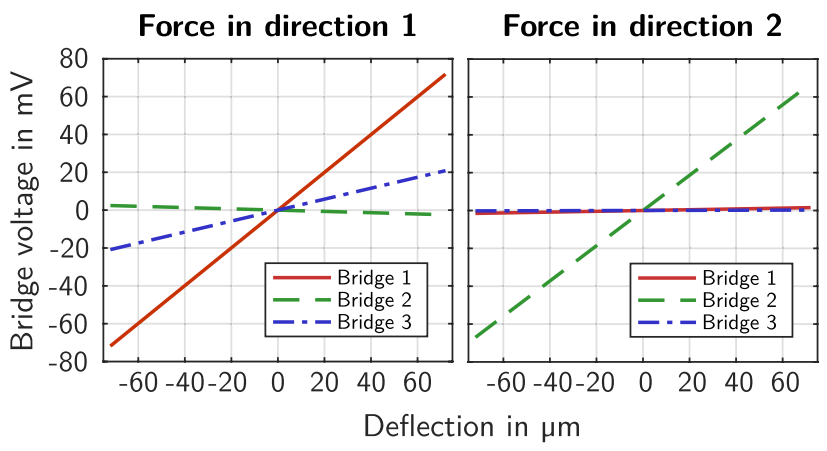

Fig. 7 Measured bridge voltages of the static tests under load in the direction of strain gauge bridges 1 and 3 (left) and 2 (right) 
modul's antenna (L1) and then perpendicular to it (L2). While the signal strength in the test series L1 is very constant at -59 to $-60 \mathrm{dBm}$, it varies more strongly at L2 with -69 to $-73 \mathrm{dBm}$. In addition, the signal strength, due to the radiation characteristics, is significantly weaker. Two additional measurement series are performed in the machine tool: at standstill (M1) and with machining speed (M2). The receiver unit is attached to the outside of the machine window so that no cables have to be routed into the interior.

At standstill, the RSSI value is even larger with -53 to $-54 \mathrm{dBm}$ than during the $\mathrm{L} 1$ tests. The metallically enclosed working space causes reflections of the electromagnetic waves which probably have a positive effect on the signal level at the receiving module. As expected, when the spindle rotates, the RSSI value varies more as the orientation of the antennas continues to change. However, with a minimum measured level of $-64 \mathrm{dBm}$, the reserve to the minimum RSSI value of $-92 \mathrm{dBm}$ is more than sufficient.

\section{Measuring the bore straightness}

As the basic functionality of the system is proven, it is used in real cutting tests. Bores were drilled in $48 \mathrm{~mm}$ thick discs of EN-GJL-250 with a bore diameter of $13.5 \mathrm{~mm}$. The pre-drilled bores are then reamed with the sensory reaming system. The reamer has six flutes made of cermet and a nominal diameter of $14 \mathrm{~mm}$ resulting in a cutting depth of $a_{\mathrm{p}}=0.25 \mathrm{~mm}$.

To measure the bore straightness, the reamer is pulled out at standstill. The spindle is turned by the NC-program so that measuring bridges 1 and 3 are aligned along the $\mathrm{x}$-axis and measuring bridge 2 along the $y$-axis of the machine tool coordinate system.

\subsection{Statistical test evaluation}

First, test data is statistically evaluated to determine the straightness from the measurement signals of the strain gauge measuring bridges. Figure 8 shows the measured bridge voltages on the $y$-axes. The $x_{\mathrm{M}}$ and $y_{\mathrm{M}}$ positions of the bore centre are measured on a coordinate measuring machine and displayed on the $x$-axis.

According to Bayesian statistics, a linear regression model is calculated for each measuring bridge. It has the form

$\mu=m U_{\mathrm{B}}+b$,

where $m$ and $b$ are parameters to be determined [13]. Using the least squares method, the parameters can be calculated
Bridge circuits 1 \& 3

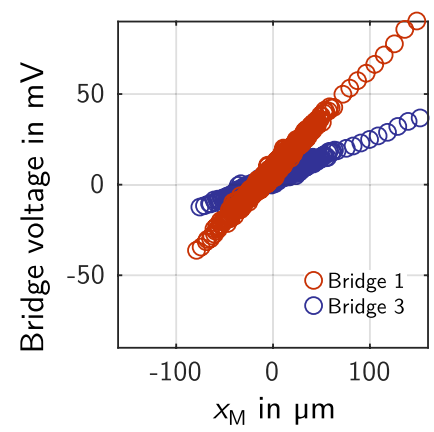

Bridge circuit 2

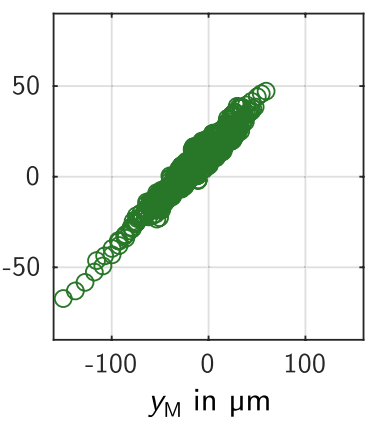

Fig. 8 Measured bridge voltages as a function of the measured bore centre coordinates

directly using the pseudo inverses. For measuring bridge 1 , the corresponding equation for $n$ available measurement values is

$\left(\begin{array}{c}m_{1} \\ b_{1}\end{array}\right)=\underbrace{\left(\boldsymbol{U}_{1}^{\mathrm{T}} \boldsymbol{U}_{1}\right)^{-1} \boldsymbol{U}_{1}^{\mathrm{T}}}_{\text {Pseudoinverse }} \boldsymbol{x}_{\mathrm{M}}$,

with

$\boldsymbol{U}_{1}=\left(\begin{array}{ll}1 & U_{11} \\ 1 & U_{12} \\ \vdots & \\ 1 & U_{1 n}\end{array}\right), \boldsymbol{x}_{\mathrm{M}}=\left(\begin{array}{c}x_{1} \\ x_{1} \\ \vdots \\ x_{n}\end{array}\right)$.

In the matrices $\mathbf{U}_{i}$ and the vectors $\boldsymbol{x}_{\mathrm{M}}$ and $\boldsymbol{y}_{\mathrm{M}}$ the measured values of the bridge voltages and the coordinate measuring machine are summarized. In addition to the calculated regression parameters, an assessment of the approximation quality is also relevant. This is done with the help of the coefficient of determination $R^{2}$, which takes values between 0 and 1 . The closer the value is to 1 , the better the measured values are approximated by the regression line. In addition, the root of the mean square error (RMSE $\hat{=}$ root mean square error) is of interest in order to be able to assess the scattering behavior. Furthermore, the 95\% confidence interval (95\% CI) of the regression parameters is calculated [18]:

$m_{i} \pm t_{\left(1-\frac{\alpha}{2} ; n-2\right)} \hat{\sigma}\left(m_{i}\right)$

$b_{i} \pm t_{\left(1-\frac{\alpha}{2} ; n-2\right)} \hat{\sigma}\left(b_{i}\right)$.

For this, the $t$ distribution for $\alpha=5 \%$ for $n$ measured values and the standard error of the estimator $\hat{\sigma}\left(m_{i}\right)$ respectively $\sigma\left(b_{i}\right)$ are needed.

In order to minimize the errors, the influence of the bridge voltages by transverse forces is compensated before the regression calculation. As shown in Fig. 7, the measuring bridges also experience a change in voltage 
Table 3 Results of the regression calculation for the estimation of the bore centre positions in dependence of the measured bridge voltages

\begin{tabular}{llll}
\hline $\begin{array}{l}\text { Measuring } \\
\text { bridge }\end{array}$ & 1 & 2 & 3 \\
\hline Estimated value & $x_{\mathrm{M}}$ & $y_{\mathrm{M}}$ & $x_{\mathrm{M}}$ \\
$m$ & 1.70 & 1.59 & 4.07 \\
$95 \% \mathrm{CI}$ & {$[1.68 ; 1.72]$} & {$[1.54 ; 1.64]$} & {$[3.98 ; 4.16]$} \\
$b$ & -11.5 & -21.3 & $-14,1$ \\
$95 \% \mathrm{CI}$ & {$[-11.8 ;-$} & {$[-22.0 ;-$} & {$[-14.7 ;-13.4]$} \\
& $11.1]$ & $20.5]$ & \\
$R^{2}$ & 0.966 & 0.831 & 0.903 \\
$\mathrm{RMSE}$ in $\mu \mathrm{m}$ & 4.50 & 10.97 & 7.58 \\
\hline
\end{tabular}

perpendicular to the direction of force. This crosstalk is calculated using the determined cross dependencies.

Table 3 shows the results of the regression calculation. Measuring bridge 1 has the best correlation, as can be expected from Fig. 8. The coefficient of determination is 0.966 , which is close to the possible maximum. At the same time, the root of the quadratic error is very small with $4.5 \mu \mathrm{m}$. It is about the same size as the positioning accuracy of the machine tool, which is $\pm 6 \mu \mathrm{m}$ according to the data sheet. The accuracy of the reaming system is therefore only limited by the positioning accuracy and can not be increased by modifications to the system.

A lower quality of the regression can be determined for measuring bridge 2 due to the greater scatter of the measured values. The RMSE value is also more than twice as large as for measuring bridge 1 . As already found in the static tests (Fig. 7), the second measuring bridge has a lower sensitivity and is at the same time more sensitive to lateral forces. For the third measuring bridge, the coefficient of determination lies between bridges 1 and 2. Because of the lower elongation at the measuring point compared to the other two bridges, and thus a greater influence of noise or other signal disturbances, the poorer correlation can be expected. However, the coefficient of determination of $R^{2}=0.903$ and an RMSE value of $7.58 \mu \mathrm{m}$ still represent good values.

\subsection{Calculation of the bore straightness with an artificial neural network}

In addition to the approach of statistical test evaluation, a determination of bore's straightness is pursued using an artificial neural network (ANN). A simple feed-forward network is used, in which the neurons of each layer are only connected to those of the following layer. There is no feedback (feed-backward). The measurement signals are given into the neurons of the input layer. From these, the calculated values are forwarded to the intermediate layer before the calculation of the desired values is finally completed in the output layer. The measured values of the reamers extraction $\left(U_{\mathrm{B} i, \mathrm{~A}}\right)$ which were already used for the statistical evaluation serve as input variables. The ANN should output the associated $x_{M}$ and $y_{M}$ values as output variables.

Depending on the number of input and output variables, the input layer consists of six and the output layer consists of two neurons. The number of neurons in the intermediate layer is determined empirically. If there are too few neurons, the network cannot approximate the relationship between input and output values with sufficient accuracy. If there are too many neurons, there is a risk of overfitting [22]. Furthermore, the computing effort for training the network increases with the number of neurons. During training, the weighting and bias values of each individual neuron are adjusted so that the error between the value to be calculated and the actual value is minimal. The algorithm is the BAYES'ian regularization approach, which is based on the BAYES statistics [20]. The available data is divided for the training. $70 \%$ serve as training data, $15 \%$ to validate the progress during training and the remaining $15 \%$ to test the network afterwards.

The performance of the network is shown in Fig. 9. It shows the correlation between the target value to be calculated by the network and the actually calculated value, separated according to the two coordinate directions. If the network were optimally adjusted, all values would lie on the straight line with a slope of "one". As with the statistical evaluation, it can be seen that the values in the $x$-direction can be approximated better than those in the $y$-direction. The regression coefficient for the $x$-direction is $r_{x}=0.993$ and for the $y$-direction $r_{y}=0.979$.

In comparison to the statistical evaluation, the neural network achieves a better approximation of the values, especially for the $y$-direction. The RMSE value in the $y$-direction is $5.16 \mu \mathrm{m}$ compared to $10.97 \mu \mathrm{m}$ for the regression calculation. In the $x$-direction, the values are also more likely to fall within a narrow range, the RMSE value is $2.87 \mu \mathrm{m}$. With the help of the ANN, it is possible to determine the centre points of the bore even more precisely on the basis of the measurement data than through the regression calculation.
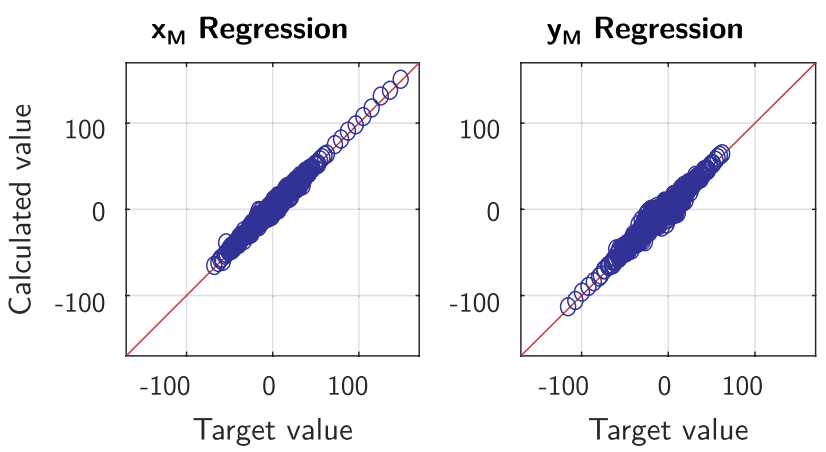

Fig. 9 Correlations between the actual values and the values determined by the trained ANN 
The initial computational effort to train the ANN is higher than that to calculate the regression parameters of the BAYES approach. While the training takes a few minutes, the parameters are calculated within a second. However, this initial effort is only necessary once. In the real production process, the measured values only have to be put into the ANN or the regression model. For the ANN, the calculation takes less than $0.1 \mathrm{~s}$ when simulating the process in Matlab. In the regression variant, the duration is less than $0.015 \mathrm{~s}$.

\section{Summary and outlook}

Reaming is an important process of fine bore machining. Process time and costs can be reduced if information about the bore quality after the reaming process are available. The bore straightness is the key criterion for the quality.

Therefore, this paper describes the development of a sensory reaming system and the investigation of its performance. Strain measurement using strain gauges is used as the measuring principle. Since the reamer and the chuck rotate in the motor spindle, wireless data transmission is necessary. For this, the development of a telemetry unit takes place, that contains all components required for analogue data preprocessing, AD implementation and subsequent transmission with the ZigBee Standard.

The analysis of the measurement data from processing experiments is carried out using two different approaches: Bayesian statistics and artificial neural network. The ANN shows the better results. It is able to determine the bore straightness very precisely. The standard error mainly caused by the positioning accuracy of the machine tool is smaller than $3 \mu \mathrm{m}$.

A few adjustments to the system are still necessary for industrial series use. In particular, a more compact telemetry unit is required, which should be integrated into the tool chuck if possible. On the one hand, this reduces the interference contour and at the same time increases the protection of the electronics against chip flight and cooling lubricant influences.

Acknowledgements The authors would like to thank the German Research Foundation (DFG) for funding the research activities at the Collaborative Research Centre "SFB 805-Control of Uncertainty in Load-Carrying Structures in Mechanical Engineering".

Funding Open Access funding provided by Projekt DEAL.

Open Access This article is licensed under a Creative Commons Attribution 4.0 International License, which permits use, sharing, adaptation, distribution and reproduction in any medium or format, as long as you give appropriate credit to the original author(s) and the source, provide a link to the Creative Commons licence, and indicate if changes were made. The images or other third party material in this article are included in the article's Creative Commons licence, unless indicated otherwise in a credit line to the material. If material is not included in the article's Creative Commons licence and your intended use is not permitted by statutory regulation or exceeds the permitted use, you will need to obtain permission directly from the copyright holder. To view a copy of this licence, visit http://creativecommons.org/licenses/by/4.0/.

\section{References}

1. Abele E, Berger M, Schmitt S (2016) Disziplinübergreifende werkzeugmaschinenentwicklung. wt Werkstattstechnik online 1/2:53-59

2. Abele E, Grosch T, Schaupp E (2016) Smart tool—intelligentes sensorgestütztes werkzeugmanagement. wt Werkstattstechnik online 106(3): 106-110

3. Adolfsson C, Ståhl J-E (1995) Cutting force model for multitoothed cutting processes and force measuring equipment for face milling. Int J Mach Tools Manuf 35(12):1715-1728

4. Arrazola P, Özel T, Umbrello D, Davies M, Jawahir I (2013) Recent advances in modelling of metal machining processes. CIRP Ann 62(2):695-718

5. Barthelma F, Aschenbach B, Neumann J (2003) Mechatronik öffnet neue wege in der zerspanung. Werkstatt und Betrieb 136(7-8):10-15

6. Bhattacharyya O, Jun MB, Kapoor SG, DeVor RE (2006) The effects of process faults and misalignments on the cutting force system and hole quality in reaming. Int J Mach Tools Manuf 46(12-13):1281-1290

7. Bhattacharyya O, Kapoor SG, DeVor RE (2006) Mechanistic model for the reaming process with emphasis on process faults. Int J Mach Tools Manuf 46(7-8):836-846

8. Boujnah H, Denkena B, Bergmann B (2018) Online compensation of tool deflection in milling operations by feeling machine tools. In: XIVth international conference on high speed machining

9. Brecher C, Eckel H-M, Motschke T, Fey M, Epple A (2019) Estimation of the virtual workpiece quality by the use of a spindleintegrated process force measurement. CIRP Ann 68(1):381-384

10. Bretz A (2019) Bestimmung der Bohrungsqualität mittels sensorischer Reibwerkzeuge. Shaker Verlag, Düren

11. Byrne G, Dornfeld D, Inasaki I, Ketteler G, König W, Teti R (1995) Tool condition monitoring (TCM) — the status of research and industrial application. CIRP Ann 44(2):541-567

12. Byrne G, O’Donnell G (2007) An integrated force sensor solution for process monitoring of drilling operations. CIRP Ann 56(1):89-92

13. Bättig D (2015) Angewandte Datenanalyse-Der Bayes'-sche Weg. Springer, Berlin

14. Cselle T, Stirnimann J (1994) Schnittkraftmessung am rotierenden werkzeug. Schweizer PräzisionsFertigungstechnik 8:77-79

15. Denkena B, Litwinski K, Brouwer D, Boujnah H (2013) Design and analysis of a prototypical sensory z-slide for machine tools. Prod Eng 7(1):9-14

16. Denkena B, Litwinski KM, Boujnah H (2016) Detection of tool deflection in milling by a sensory axis slide for machine tools. Mechatronics 34:95-99

17. Ehmann KF, Kapoor SG, DeVor RE, Lazoglu I (1997) Machining process modeling: a review. J Manuf Sci Eng 119(4B):655-663

18. Eid M, Gollwitzer M, Schmitt M (2017) Statistik und Forschungsmethoden. Beltz Verlag, Weinheim

19. El-Wardany T, Gao D, Elbestawi M (1996) Tool condition monitoring in drilling using vibration signature analysis. Int J Mach Tools Manuf 36(6):687-711 
20. Foresee FD, Hagan MT (1997) Gauss-Newton approximation to Bayesian learning. In: Proceedings of international conference on neural networks (ICNN'97), vol 3. IEEE, pp 1930-1935

21. Fulemova J, Kutlwaser J, Gombar M, Rehor J (2017) Influence of selected technological factors on the hole quality during reaming. Ann DAAAM Proc 28:334-340

22. Hagan MT, Demuth HB, Beale MH, De Jesús O (2014) Neural network design, vol 20. Pws Pub, Boston

23. Jun MB, Ozdoganlar OB, DeVor RE, Kapoor SG, Kirchheim A, Schaffner G (2002) Evaluation of a spindle-based force sensor for monitoring and fault diagnosis of machining operations. Int $\mathbf{J}$ Mach Tools Manuf 42(6):741-751

24. Kasprzak M (2015) Design and implementation of wireless module based on ZigBee for applications in machine tools. J Mach Eng $15: 133-143$

25. Kern S (2009) Erhöhung der Prozessstabilität durch aktive Dämpfung von Frässpindeln mittels elektromagnetischer Aktoren. Shaker, Düren

26. Kistler (2018) 4-Komponenten dynamometer 9170A. Kistler Instrumente $\mathrm{GmbH}$, Sindelfingen

27. Klocke F, Gierlings S, Adams O, Auerbach T, Kamps S, Veselovac D, Eckstein M, Kirchheim A, Blattner M, Thiel R et al (2012) New concepts of force measurement systems for specific machining processes in aeronautic industry. Proc Cirp 1:552-557

28. Klocke F, Kuljanic E, Veselovac D, Sortino M, Wirtz G, Totis G (2008) Development of an intelligent cutter for face milling. Strain $14: 15$

29. Klocke F, Wirtz G, Veselovac D, Totis G (2008) Entwicklung eines mehrschneidigen messerstirnfräskopfes mit einzelschneidenkraftmessung. ZWF Zeitschrift für wirtschaftlichen Fabrikbetrieb 103(11):762-765

30. Kong MC, Axinte DA, Wilson B, Marinescu I, Allen J, Raffles M, Weston S (2012) An innovative design of multi-task dynamometers for turning operations. Proc Inst Mech Eng Part B J Eng Manuf 226(6):1118-1124

31. Kuhfuß B, Allers S (2009) Sensing tool for condition monitoring. In: 9th international conference and exhibition on laser metrology, machine tool, CMM and robotic performance

32. Kuhfuß B, Allers S, Schädlich S (2009) Sensor- und aktorintegration in rotierende werkzeuge. In: 6. Paderborner Workshop "Entwurf mechatronischer Systeme", pp 59-69

33. Kuljanic E, Sortino M, Totis G (2008) Multisensor approaches for chatter detection in milling. J Sound Vib 312(4-5):672-693

34. Lauro C, Brandão L, Baldo D, Reis R, Davim J (2014) Monitoring and processing signal applied in machining processes-a review. Measurement 58:73-86

35. Liu M, Zhou Z, Tao X, Tan Y (2012) A dynamometer design and analysis for measurement the cutting forces on turning based on optical fiber bragg grating sensor. In: 10th World Congress on Intelligent Control and Automation (WCICA), 2012. IEEE, pp $4287-4290$

36. Maier W, Möhring H-C, Werkle K (2018) Tools 4.0-intelligence starts on the cutting edge. Proc Manuf 24:299-304. 4th international conference on system-integrated intelligence: intelligent, flexible and connected systems in products and production
37. Mathews P, Shunmugam M (1999) Condition monitoring in reaming through acoustic emission signals. J Mater Process Technol 86(1-3):81-86

38. Mathews P, Shunmugam M (1999) Neural-network approach for predicting hole quality in reaming. Int J Mach Tools Manuf 39(5):723-730

39. Michel S (2017) Sensorlager als datensammler wird standardprodukt. Maschinenmarkt 04

40. Niu Y, Wong Y, Hong G, Liu T (1998) Multi-category classification of tool conditions using wavelet packets and art2 network. J Manuf Sci Eng 120(4):807-816

41. promicron (2018) Sensorischer Werkzeughalter spike. pro micron GmbH \& Co. KG, Kaufbeuren

42. Rizal M, Ghani JA, Nuawi MZ, Haron CHC (2015) Development and testing of an integrated rotating dynamometer on tool holder for milling process. Mech Syst Signal Process 52:559-576

43. Santochi M, Dini G, Tantussi G, Beghini M (1997) A sensor-integrated tool for cutting force monitoring. CIRP Ann 46(1):49-52

44. Schiffler A (2011) Steuerungsintegrierte Prozessüberwachung bei der Zerspanung mit Motorspindeln. Shaker, Düren

45. Schulz H, Versch A, Fiedler U (2001) Process monitoring with mechatronic tool holders. Prod Eng Res Dev 8(2):115-118

46. Smith D, Smith S, Tlusty J (1998) High performance milling torque sensor. J Manuf Sci Eng 120(3):504-514

47. Teti R, Jemielniak K, O’Donnell G, Dornfeld D (2010) Advanced monitoring of machining operations. CIRP Ann Manuf Technol 59(2):717-739

48. Totis G, Sortino M (2011) Development of a modular dynamometer for triaxial cutting force measurement in turning. Int J Mach Tools Manuf 51(1):34-42

49. Totis G, Wirtz G, Sortino M, Veselovac D, Kuljanic E, Klocke F (2010) Development of a dynamometer for measuring individual cutting edge forces in face milling. Mech Syst Signal Process 24(6): $1844-1857$

50. Versch A (2004) Steigerung der Prozesssicherheit durch sensorintegrierte Werkzeugaufnahmen. Shaker, Düren

51. Xiao C, Ding H, Cheng K, Chen S (2015) Design of an innovative smart turning tool with application to real-time cutting force measurement. Proc Inst Mech Eng Part B J Eng Manuf 229(3):563-568

52. Xie Z, Lu Y, Li J (2017) Development and testing of an integrated smart tool holder for fourcomponent cutting force measurement. Mech Syst Signal Process 93:225-240

53. Yaldız S, Ünsaçar F, Sağlam H, Işık H (2007) Design, development and testing of a four-component milling dynamometer for the measurement of cutting force and torque. Mech Syst Signal Process 21(3):1499-1511

Publisher's Note Springer Nature remains neutral with regard to jurisdictional claims in published maps and institutional affiliations. 